New Zealand journal of industrial relations, 1991, 16, 37-47

\title{
Occupational health and safety legislation: what else is needed?
}

\author{
Ian Campbell*
}

If regulation is to be effective, not only must changes take place in the mode of regulation but also the concepts held by many in management ranks. Misconceptions often abound which, it is suggested, stem from a lack of appreciation of accident causation, the part that the management system plays or a tendency to blame the victim. Thus, too much attention continues to be paid to operator error, whereas in reality, it is frequently the organization that has failed. However, when management recognizes the pivotal role of the system, and makes greater use of quality control methods, the way will be open for the inspectorate also to be more innovative. They will then be initially auditors of the management of the occupational health and safety policy. Without that change the enforcers will, of necessity, continue to be searchers for violations and investigators after the event. It is also likely that the health hazards of the working environment will continue to be given inadequate attention. With the introduction of the Occupational Safety and Health Bill into Parliament in 1990, followed by a change of government bringing its new agenda and thus casting an ominous shadow of concern, such factors assume a greater degree of importance.

\section{Introduction}

Though the conclusions of many studies that have attempted to measure the effectiveness of occupational health and safety legislation have been a little disappointing to say the least, over time, much has been accomplished. As we have learned how to cope with many of the more obvious hazards, mainly of a broadly physical or mechanical nature, modern technology has brought many new challenges in its wake. For example, who would have envisaged 30 or more years ago, that we would now be concerned with health problems in the ordinary office; previously thought to be, and which mostly was, the most benign of environments. Again, until relatively recently the emphasis has almost exclusively been on safety factors and, though much is now changing, one must question whether the recognition of the health hazards of the working environment is proceeding fast enough.

In addition to considering developments in other countries and the indications for change set out in the more recent conventions of the International Labour Organization, it is also logical to examine some of the reasons why so many negative attitudes still abound. Why, for example, is there not more enthusiasm for a participative approach or a greater determination to deal more effectively with the health hazards of the working environment? Our very dilatory approach to the problems of asbestos is glaring evidence of the chronic inertia that has plagued New Zealand for too many years. Many will see

* Teaching Fellow in Safety and Occupational Health, Massey University. 
some hope for improvement in the Occupational Safety and Health Bill but are there roadblocks ahead? Prior to the 1990 General Election National Party spokesman on industrial relations, Bill Birch, is reported as saying: "if the Bill does survive the election, National's changes will make it unrecognisable." (National Business Review, 28 August 1990, p.4). If we are not to perpetuate the seeming indifference of past authorities to change, then both the need for change and the factors keeping past prejudice alive need to be discussed, better understood and adverse influences countered. That is the objective of this paper.

\section{Recent legislative changes elsewhere}

What then are the indications from the more recent developments overseas? Unfortunately, whereas we once led the world in many of our innovative approaches, except for accident compensation, that appears to be no longer the case? It is certainly so with respect to occupational health and safety legislation, for while other countries have taken up the challenge of new approaches, we have lagged behind. That being so, what have we been missing? Since the Robens Report (Safety and health at work, 1972) much emphasis has been placed on the need for self-regulation, even though that particular aspect of the report has drawn a lot of criticism. Certainly Robens, as with any other report, contains much that can be criticized but are all those criticisms justified? Surely the points that one can criticize should not be allowed to obscure the indisputable facts that it emphasizes or well-reasoned arguments for change.

There are decided limits to the range of regulation itself, and to its enforcement. Thus appropriately, the principal message from Robens is the need to impress the responsibility of and need for action by "those who create the risks and those who work with them" (Safety and health at work, 1972, p.7). That view then leads quite naturally to a call for a more participative approach, a call that has not met with universal approval, despite its sheer logic. One could well ask whether the words "self-regulation" lack appeal, are misunderstood and even counter-productive. Interestingly in Canada, Dr James Ham sitting as a Royal Commissioner examining the health and safety of workers in Ontario mines embraced the same principles but expressed himself a little differently using the words: "internal responsibility system" stating:

\footnotetext{
The acceptable levels of risks at work and in life-style are being redefined by society. It is essential that this process be marked by a higher measure of openness than has hitherto characterized government and industrial policy. Openness, contributive participation by workers, and thorough accountability can re-establish the self-regulatory character of the internal responsibilitysystem at the company level as the key to the control of risks at work in a technologically complex future. The regulatory and auditing functions of the Occupational Health and Safety Authority should be designed to keep the internal system at company level alert and responsive and to deal bluntly with the true offender (Report of the Royal Commission, 1976, p.250)(emphasis added).
}

It is strongly contended that the key lies in the last sentence but more of that later. Though concerned with mines, this report led to the passing of the Ontario Occupational Health and Safety Act 1978, a statute similar to the post-Robens British Health and Safety at Work Act 1974 and much other Canadian and Australian legislation. 


\section{The participative approach}

In Canada, where considerable emphasis has been laid on committees, worker involvement has proceeded against a background of 3 important principles. They are:

(a) a worker's right to know the hazards faced;

(b) a worker's right to participate in the determination of health and safety measures; and

(c) a worker's right to refuse to undertake work where there is reasonable justification for so doing on the grounds of health and safety.

Joint management-labour health and safety committees have had a chequered history, being frequently viewed with apprehension by management and cynical suspicion by labour. In the past, far too many committees have been established with no or inadequate terms of reference in an atmosphere which is more adversarial than of compromise and cooperation. Training of committee members, both management and labour, has been conspicuous by its absence, yet it is now accepted by those with considerable experience in the field that adequate training, along with complete access to all technical details of the hazards faced, is absolutely essential. Despite this unpromising state of affairs, recent legislation in many countries now calls for the establishment of joint committees and the appointment of workers' health and safety representatives. In many cases this has become mandatory within defined limits.

What also needs to be emphasized is that the participative approach as envisaged in this paper involves an essential change. In the past, great emphasis has been based on improving worker attitudes; a concept arising from a conviction that accidents were frequently a consequence of such factors as carelessness, inattention or accident proneness. This has led, at times, to considerable use of what could be described as gimmicky promotional methods, safety contests, undue reliance on posters and other publicity material and approaches all dedicated to encouraging changes in the behaviour and attitudes of workers. That is not to say that such methods do not have some use but their place is very much a supportive role not the main thrust, for they overlook the vital part that the organization, its systems and management play in setting the stage for an efficient workplace.

It also follows that if there is not adequate worker participation, and the view remains firmly held that given such opportunities and rights workers will only abuse them, then the stage is set for a continuation of the present unsatisfactory situation. If there is a lack of trust on the part of employers it would be hardly surprising if the employees also showed a similar lack of trust. Those who would resist greater worker involvement could well heed the following comments of Carson:

Those who resist this suggestion on the grounds that organized labour will merely make use of health and safety issues for ulterior purposes must be challenged to confront the logic of their own argument. Are they really prepared to defend the proposition that, whereas trade unions cannot be trusted not to allow baser instincts to colour their approach to occupational health and safety issues, somehow or other management and employers can? (Carson, 1985 , p.75).

Carson then suggested that such a proposition would mean "that genuine disinterestedness and the capacity to transcend sectional interest are distributed according to social class" (Carson, 1985, p.75).

In an International Labour Office report (1980) prepared just before Convention 155 was adopted, the following interesting comment appears after referring to the appointment of both joint committees and workers' health and safety delegates: 
It appears nevertheless that, as a general rule, the system of workers' safety delegates is regarded as the more efficient, especially where they enjoy wider rights. Such delegates are in a position to follow on the spot and continuously the flow of operations whereas members of safety committees visit workplaces only from time to time and, as a rule, play only an advisory role (p.19).

How then are these committees and workers' health and safety representatives performing? Responses to such a question would vary widely but it is clear that, properly structured, adequately trained, supported, and given access to essential information on the hazards with which they have to contend, they can perform a most useful function.

In one of a number of studies commissioned for an Ontario Royal Commission, Gunderson and Swinton, when attempting to make an assessment of the efficacy of joint committees, commented:

First, it appears that joint committees will work better in organized than nonunionized workplaces. Even if [Ontario Federation of Labour] training is available to nonunion workers, they are lacking in a general support system to assist them in establishing a committee and providing resources to deal with problems as they arise. This is particularly true with regard to recognition of health hazards and responses to them. The employees may often be in marginal companies, where pressure on health and safety issues may be perceived as a threat to employment security.

Secondly, the committee's input may be more problematic with regard to health issues than with safety issues. Information problems are severe, for it may be difficult for workers to acquire information on chemicals or other toxic substances in their work environment, particularly if a trade name is used. Certainly the Ministry of Labour study on voluntary committees found that "health issues are conspicuous by their near absence, particularly in those industries with recognised health problems" (Gunderson and Swinton, 1981, p.8.21).

After suggesting that, even accepting some of the shortcomings outlined, they comment that "the joint committee is, however, an improvement on the situation with no joint committees." And later:

Where management is cooperative with the joint committee, the joint committee can have a valuable input into control of health hazards. This may take the form of designing education programs, discussing new safety rules and communicating them to workers, or working with management on the phasing out of the hazard (Gunderson and Swinton, 1981, p.8.22).

Unsatisfactory aspects of the past performance of such committees should not be allowed to stultify progress. When one's eye is firmly glued to the rear vision mirror of past attitudes, experience and convictions, little will be seen of the road of progress which still lies ahead. Many managements are still very reluctant to see greater worker involvement in occupational health and safety or any participation by the workforce in trade union education. If progress is to be made such views need to be countered. On the other hand, others would maintain that more trade union involvement in occupational health and safety is long overdue, though unions themselves are stepping up their own educational programmes. 


\section{The importance of the management system}

Accepting the value of committees and representatives, it is suggested that it is the total management system which is the vital factor, and certainly the essential basis for an effective internal responsibility system. There is thus a considerable scope for wide ranging changes in New Zealand and elsewhere and, certainly, in the immediate future. Clearly the success of the participative approach is predicated to a substantial shift in management attitudes which it is later suggested stem from misunderstandings, misconceptions and in some cases ingrained prejudice. How else could the Business Roundtable (1988, p.17) argue that:

[w]hile there may be some case for legislation setting out the basic rights of workers with regard to health and safety issues, the optimal legislation need not involve disclosure rules. Because information disclosure is not always feasible or desirable, it is possible that this role may be more appropriately played by clarifying employers' duty of care, or by introducing some form of negligence tort, with information disclosure being taken into account in determining responsibility/negligence.

Considering the emphasis that the Roundtable place on enterprise bargaining providing a better base to develop greater efficiency, productivity and industrial harmony, one would have assumed that a well informed workforce would have been essential to its success. Clearly their motives for opposing information disclosure warrant close examination. Surely equity in such negotiations can only begin to exist if there is today's much lauded arena, the level playing field. The cost of information is also mentioned and they even go on to suggest that research in this area be commissioned by employers and/or workers. Then there follows a claim that there is evidence (from the United States) that government agencies consistently overestimate risks. However, there is other evidence, also from the United States. Epstein comments:

Industry has manipulated economic as well as scientific data. It is now common practice for any industry when "threatened" by an impending regulation or standard designed to protect against occupational cancer, environmental pollution, or some other adverse effect, to protest that this measure is unnecessary and so expensive that it will put the industry out of business (Epstein, 1978, p.312).

As Tafler confirms, reporting that when Occupational Safety and Health Administration proposed a new standard for polyvinyl chloride, at the hearing the plastics industry presented studies predicting a loss of $\$ 69-90$ billion and about 2 million jobs. Actually, the real cost of compliance was about $\$ 325$ million in capital and a loss of 290 jobs through the closing of 2 obsolescent plants (Tafler, 1982, p.76). Again, writers like Castleman and Ziem (1988) confirm these contrary views and are very critical of the threshold limit values advocated by the American Conference of Government Industrial Hygienists. They criticize the lack of comprehensive documentation to back up the threshold limit values as well as the undue influence industry representatives have played in setting those standards (p.554). Indeed, it would seem that many standards have been set by the manufacturers themselves, and they are obviously interested in keeping the level as high as possible. These factors are of vital interest to New Zealand for it is on these standards that we too rely, to determine the acceptable level of airborne toxins and other contaminants in the workplace. 


\section{Causation}

It is insufficiently recognized that accidental injury and work-related disease seldom occurs as the result of one factor alone, for most injuries arise as a result of several factors some of which may be completely unrelated. Then there could be differences in injury reporting, not forgetting that each does not have the same threshold of pain. Much of this misunderstanding stems from inadequate investigation of accidents and their causation. For too long attention has been focussed on unsafe acts and conditions and the hasty determination of a single cause. Often inquiry has concentrated on the obvious, ignoring the real underlying causation and, sometimes, emotional factors may play too large a part in a determination. Thus with good reason have some writers expounded on the myth of the careless worker. Today, for example, among other developments, ergonomics is giving us a greater insight into causation.

\section{Victim blaming}

Under this heading, it is suggested, lies another of the reasons why more progress has not been made, especially in harnessing the management system and the participatory approach. Out in the community and in the workplace, there is still a lot of negativism about occupational health and safety which must be countered and overcome if real progress is to be made. Many hold a conviction that numerous accident victims are the authors of their own misfortune. True, often a superficial examination of the circumstances surrounding an accident will suggest that to be the case but one needs to look deeper. The underlying cause of many accidents can only be determined by a thorough and objective investigation of all the circumstances.

\section{The accident proneness theory}

The accident proneness theory, which stems from studies made among munition workers during World War I, has been responsible for one of the most unprofitable debates in the safety field. What is worse, it has, on occasions, been used to the detriment of genuine preventive measures, often as an excuse for inactivity. One of the more detailed studies, that of Arbous and Kerrich (1951, p.363), comments that this concentration on personal attributes has resulted in ".... an attempt to shift the blame from the environment to the individual, calling people and not workplaces, accident prone".

These aspects need to be examined and put in their proper perspective. Obviously all people do not have the same degree of perception, coordination and dexterity and thus even in a group of similar individuals, there will be differing degrees of performance. Furthermore, one's ability to undertake a particular task is not constant and may vary in response to a host of factors including health, personal problems and stress in its many forms, all of which may vary over time.

Much misunderstanding has been caused by the widely differing concepts, that many have concerning accident proneness, a term that can be subject to numerous and diverse interpretations. Several factors enter into the argument and clearly the first to consider is causation. It cannot be assumed that an injured person may be even partially the author of his or her own misfortune. Even in cases where a person may be plainly guilty of some inattention or disregard of rules, one needs to look further. There may have been some external factors influencing events such as pressure to complete a task, tiredness brought on by long working hours or family problems. 
In addition to the very comprehensive paper of Arbous and Kerrich, the other major work undertaken in recent years is that by Shaw and Sichel. Their concluding chapter begins somewhat realistically:

It would be very gratifying to be able to end this section of the book by giving clear-cut answers to the two basic questions: "Is accident proneness a myth or a reality? and "If it is a reality, how much does it matter in the accident situation as a whole?"(Shaw and Sichel, 1971, p.416).

\section{And finally:}

But something which I have also tried to do is to show how research on accident proneness has done rather more than uncover many of the reasons why individual people have accidents. It has shown that one of the potent reasons why accidents happen at all, is that they are encouraged rather than prevented by the prevalent attitude of the community to the whole accident problem especially in those countries where accident rates are still unnecessarily high (Shaw and Sichel, 1971, p.421).

In like vein, Sass and Cook (1981, p.107) conclude another examination of the various studies that have been undertaken against the background of the typical work situation:

If all this is combined with a dangerous physical work environment or hazardous work processes, then accidents are bound to take place. Telling workers not to have accidents is simply not a preventive measure, as accident liability is inherent in the very nature of the work. Blaming the victims for accidents is also fruitless, since it does not provide impetus for the elimination of hazardous conditions. In this respect, the accident proneness thesis has not been a benign scientific error. Its introduction may have been accompanied by the best of intentions, but its unquestioning acceptance and widespread use have obscured the need for development of a holistic approach toward understanding and preventing industrial accidents in light of the dynamic interaction between the socio-technical work environment and workers.

What appears to be overlooked by those who make much of the proneness theory, even accepting there will be some who are more likely to be injured than others, is their failure to determine to what practical use that knowledge can be put. Can those individuals be identified and restricted to activities where their unfortunate characteristics will no longer be a risk and, if so, upon whom will such decisions fall? In the end perhaps the most disastrous effect of the whole debate is the emphasis it has given to the tendency to blame the victim and not to seek the basic causation.

\section{The influence of economic conditions}

Another factor which we have to accept today is the effect of the downturn in the economy, when the whole scene can well change. As Glendon and Booth comment when examining more recent developments in Britain:

Since about 1979 , however, there has been a decline in such activity [trade union stimulus]. Increasing worker expectations regarding health and safety generated since the mid-1970s are now coming into conflict with the effects of the economic recession, which operate to reduce expenditure on health and safety and concomitantly increase redundancy fears and channel trade union activity more towards job preservation. Despite increasing worker concern about the work environment, trade unions have greater difficulty in pressing 
health and safety demands in an adverse economic climate ... There is still only limited backing for safety representatives from the trade unions at industry and national level, and there are some signs of a shift towards hazard-oriented national campaigns by trade unions (Glendon and Booth, 1982, p.412).

\section{Supplementing regulation: quality and safety}

At this point it is interesting to recall the words of Heinrich whose text, first published in 1931, is regarded as the beginning of the scientific approach to occupational health and safety when he commented:

The control of quality and quantity of product and of the frequency and severity of accident occurrence have much in common. In many cases the same faulty practice is involved, and the reason for existence of the fault is similar, both for accident occurrence and for unsatisfactory production (Heinrich, 1941, p.40).

In view of Heinrich's linking of accident frequency with quality 60 years ago, it in interesting to see that now that view is emerging again.

Much more needs to be done to emphasize that compliance with regulatory provisions alone, will not ensure the safest or healthiest possible workplace. Regulation needs to be so designed and enforced that attention is first focussed on the management of the organization, its systems and quality controls. In a review of the health and safety legislation administered by the Maritime Division of the New Zealand Ministry of Transport much emphasis was laid on quality control. After referring to the work of Dr Edwards Deming (1982, p.352) in Japan, immediately following the World War II, where he stressed the importance of statistical methods and quality control the report goes on to stress the relationship between quality and safety commenting:

Why have we been talking about quality when we are supposed to be concerned with safety? Because the two are inextricably intertwined, in fact safety is a subset of quality. We can show this axiomatically. Let us take Deming's definition of quality - a product or service supplied reliably according to specification - and let the required safety levels be part of the specification. Then it automatically follows that the product will be a safe product. This principle applies to the manufacture and maintenance of all products with which the Maritime Transport Division is involved, such as boilers, lifts, cranes, pressure and refrigerant vessels, ships and boats.... Putting it another way; a quality product is a safe product, a quality maintenance system is a safe maintenance system (D'Souza et al., 1989, p.51).

\section{Under the heading "Cultural factors" the report continues:}

These quality-system principles are only effective if quality is part of the culture of the whole firm, from top-management down. Preferably they should be accepted throughout the sector in which the firm operates, and better still they should be a feature of the national culture. At the level of the firm, for example, it would be futile to try to build a quality product in a slipshod factory. Lipservice and buzzwords will not produce quality and safety .... Here again we stress that such values need to be reinforced by the total national environment they should be evident in the behaviour of managers and the leaders of society. Such changes cannot be produced overnight. Time and effort will be required to bring them about (p.51).

Though many may feel that such an approach is not for the average undertaking that is not so. Quality of product or service should be the aim of every undertaking large and 
small. The Testing Laboratory Registration Council provides a straight forward quality system called Q-Base Code for small firms.

The claim, that not only would such an approach markedly improve occupational health and safety but also have considerable spin-offs in quality and the general efficiency of production nationally, deserves the greatest consideration. These points are well made in a National Institute for Occupational Safety and Health research report (Cleveland $e t$ al., 1979). Unfortunately many New Zealand managers have yet to be convinced. Certainly many with some experience of the international safety rating system first introduced by the Accident Compensation Corporation some years ago could testify to the benefits of such an approach.

\section{The Occupational Safety and Health Bill 1990}

Finally we turn to the most recent attempt to move a little more rapidly down the road to improvement. While this Bill had many highly desirable features, features absolutely essential to progress, there were some disappointing aspects. Probably the greatest need is for there to be a more cooperative approach in the workplace itself and between the workplace and the enforcement agency. To some it is incredible that the recommendations to be found in Occupational safety and health reform (Advisory Council for Occupational Health and Safety, 1988) which represents the views of not only employer and worker interests but also those of Government agencies was not given greater consideration. To examine those recommendations in detail.

\section{A tripartite commission}

The report recommended a tripartite commission accountable to the Minister and responsible for developing and implementing policy. This recommendation has been watered down to a bipartite commission with an advisory and promotional role. While that approach may stem from the well publicized aversion to quangos, most will see it as a lack of confidence on the part of the politicians, probably fuelled by apprehension on the part of their public service advisers. In Victoria and West Australia, the corresponding Commission also includes members who are appointed for their special expertise in occupational health and safety. There is no mention in the Bill that would require that the commission be adequately staffed. Section 20 of the 1985 Victorian Act, for example, provides that "there shall be appointed such officers and employees as are necessary to assist the Commission in the performance of its functions and duties." After all, the lack of any forward-thinking moves over the past few decades are clear indicators of a reluctance to change. Furthermore, in reality, the changes suggested by the Advisory Council for Occupational Health and Safety pale into insignificance when viewed against much that has happened in the public sector in recent years.

\section{An authority}

The recommendation for an authority to be the administrative and operational arm of the Commission has not been accepted. Instead the functions of other departments would be transferred to the Labour Department. The reluctance of departments to yield functions to another department is well known and understandable. However had the recommendation to establish a stand alone authority, to which functions would have been transferred from all departments, then the opportunity would have been presented to that new body to build up a new culture. It is suggested that the end result would have been a much more effective and cohesive body. 


\section{An institute}

The proposal for an institute to be the technical, scientific and research arm of the commission has faded into obscurity. The efforts of the Health Department to establish adequate technical, scientific and research resources over the last 3 decades have only met with limited success despite the very determined efforts on the part of a small number of very dedicated officials. Regrettably, the events of the recent past have seen a dismembering of most of what remained. The technical support needed by the inspectorate now comes from the Area Health Boards which do not all have the same ability to meet the needs. The recommendations of the Advisory Council for Occupational Health and Safety thus remain but a pipe dream. If the health hazards of the working environment are to be accorded adequate consideration, to say nothing of the safety aspects, then it is essential that the Advisory Council for Occupational Health and Safety recommendations be given the consideration that is their due.

Unfortunately the rather pessimistic forebodings of Mullen (1990, p.141) appear to be warranted.

\section{A final comment}

Though the words "worker participation" have received considerable airing of recent years, one could well question whether that emphasis is justified. Should not a much wider view be taken, for clearly all sectors must participate and for that reason it is suggested that a "participatory approach" better describes what is needed.

If regulation is to achieve its full potential, then it is suggested that there must be a considerable change in the approach of many, particularly those in the management team. In the long run, it is their systems that are on trial. If the considerable supportive role, that a participatory regime can play, is to be effective, then the negative factors such as victim-blaming, misapprehensions about causation and a sceptical if not an antagonistic view of the value of committees and workers' representatives need to be completely eliminated. One could well question whether the new government has been influenced by the less progressive elements of the employer ranks for their spokesman to indicate that they would "make unrecognisable," the far from revolutionary bill that was presented to Parliament in 1990. If those attitudes and influences are to remain unchanged and persist, then improvement in the occupational health and safety field so many have been seeking will remain but a dream.

However with management recognising the pivotal role of the system, and with greater use of quality control methods, the way will be open for the inspectorate also to be more innovative. They will then be primarily auditors of the undertaking's management of the occupational health and safety policy, rather than mere searchers for non-compliance. Such an approach is always predicated to Dr Ham's edict that the true offender must be dealt with bluntly. Nevertheless, in the end, if regulation continues to be viewed as the main or even the ultimate protector of workers' lives, then we will have failed.

\section{References}

Advisory Council for Occupational Safety and Health (1988) Occupational safety and health reform. Wellington.

Arbous, A.G. and Kerrich, J.E. (1951) Accident statistics and the concept of accident proneness. Biometrics Part 1(7):341-390.

Business Roundtable (1988) Regulating for occupational safety and health. Wellington. 
Carson, W.G. (1985) Hostages to history: some aspects of the occupational health and safety debate in historical perspective. In B. Creighton and N. Gunningham (eds.) The industrial relations of occupational health and safety. Sydney, Croom Helm.

Castleman, B.I. and Ziem, G.E. (1988) Corporate influence and the threshold limit values. American journal of industrial medicine 13: 531-559.

Cleveland, R., Cohen, H.H., Smith, M.J. and Cohen, A. (1979) Safety program practices in record-holding plants. Morgantown, WV, National Institute for Occupational Safety and Health.

Deming, W.E. (1982) Quality, productivity and competitive position. Cambridge, Ma., MIT Press.

D'Souza, K., Aldridge, W., Belt, K., Campbell, I.B. and MacKenzie, H. (1989) Quality and safety systems. Wellington, Maritime Transport.

Epstein, S.S. (1978) Constraints in decision making. Annals New York Academy of Sciences 329: 309-317.

Glendon, A.I. and Booth, R.T. (1982) Worker participation in occupational health and safety in Britain. International labour review 121(4): 399-416.

Gunderson, M. and Swinton, K. (1981) Collective bargaining and asbestos dangers at the workplace. Toronto, The Royal Commission on matters of health and safety arising from the use of asbestos in Ontario.

Heinrich, H.W. (1941) Industrial accident prevention: a scientific approach. New York, McGraw Hill (2nd edition).

International labour office (1980) Safety and health and the working environment report VII(a)(1). Geneva.

Mullen, E.A. (1990) Voluntarism in occupational health and safety: the New Zealand response. New Zealand journal of industrial relations 15(2): 129-143.

Report of the Royal Commission on the health and safety of workers in mines (1976). Toronto, Ministry of the Attorney General.

Safety and health at work: Report of the Committee (Robens Report) (1972) Cmnd 5034. London, HMSO.

Sass, R. and Cook, G. (1981) Accident proneness: science or non-science. International journal of health services 11: 175-190.

Shaw, L. and Sichel, S. (1971) Accident proneness. Oxford, Pergamon.

Tafler, S. (1982) Cost-benefit analysis proves a tough task. High technology 2(4): 7677. 